\title{
Xylitol biological production: a review of recent studies
}

\begin{abstract}
Xylitol is an alternative sweetener that is recommended for use in food and pharmaceutical products, as it has some health benefits. It is currently produced on a large scale using a chemical reduction that requires high energy and is costly. Biological conversion of xylitol using microorganisms is an alternative process that is environmentally friendly and costeffective. This process has been studied in an effort to provide one that is high yielding and competitive with chemical processes. This article reviews recent studies in the development of biological conversion processes for the production of xylitol, including biomass conversion, fermenting microorganisms, and new technology for full-scale process development.
\end{abstract}

Keyword: Bioengineering; Biomass; Xylitol; Xylose; Yeast 